\title{
Perception of Bronchial Obstruction in Asthmatic Patients Relationship with Bronchial Eosinophilic Inflammation and Epithelial Damage and Effect of Corticosteroid Treatment
}

Gabriel L. Roisman, * Claudine Peiffer, * Jacques G. Lacronique, * Ariane Le Cae, ${ }^{\star}$ and Daniel J. Dusser

*Service de Pneumologie and ${ }^{\ddagger}$ Service d'Anatomopathologie, Unité de Formation et de Recherche Cochin-Port-Royal, Université René Descartes, Paris, France

\begin{abstract}
We studied the perception of bronchoconstriction in asthmatic subjects who were randomly treated with inhaled $\beta_{2}$ agonist given either alone $(n=9)$ or associated with inhaled corticosteroids $(n=9)$. Methacholine and bradykinin challenges, bronchoalveolar lavage, and bronchial biopsies were performed in all subjects. After each dose of agonist, breathlessness was assessed using a visual analog scale (VAS) and the forced expiratory volume in $1 \mathrm{~s}\left(\mathrm{FEV}_{1}\right)$ was measured. The relationship between VAS scores and $F V_{1}$ and the slope of the regression line of VAS scores on the corresponding FEV $_{1}$ (VAS/FEV 1 slope) were analyzed for each agonist.

Subjects without corticosteroids had good perception of methacholine but poor perception of bradykinin-induced bronchoconstriction. In subjects with corticosteroids, bronchoconstriction was well perceived whatever the agonist. VAS/FEV 1 slopes for bradykinin but not for methacholine correlated negatively with the magnitude of eosinophilic inflammation in airway mucosa. VAS/FEV 1 slopes for each agonist correlated positively with the percentage of basement membrane covered by airway epithelium.

We conclude that in asthmatic patients perception of bronchoconstriction is related to eosinophilic inflammation and to epithelial damage in airways and that corticosteroid treatment is associated with improved perception of bronchoconstriction induced by bradykinin, a mediator endogenously produced in asthma. (J. Clin. Invest. 1995. 96:1221.) Key words: dyspnea • bronchial asthma • bronchoconstrictor agents $\bullet$ inflammation $\bullet$ eosinophils
\end{abstract}

\section{Introduction}

Patients with asthma vary greatly in their ability to perceive spontaneous bronchoconstriction $(1,2)$ and to quantify the breathlessness associated with acutely induced bronchoconstriction $(2,3)$ or with spontaneous variations of airway flow that occur during normal daily life (4). Poor perception of the severity of bronchoconstriction in asthma may lead to a delay in starting appropriate treatment which is possibly one of the fac-

Address correspondence to D. J. Dusser, Service de Pneumologie, Hôpital Cochin, 27, rue du Fg Saint Jacques, 75679 Paris Cedex 14, France. Phone: 1-42-34-15-51; FAX: 1-46-33-82-53.

Received for publication 26 July 1994 and accepted in revised form 2 February 1995.

J. Clin. Invest.

(C) The American Society for Clinical Investigation, Inc.

0021-9738/95/07/0012/10 \$2.00

Volume 96, July 1995, 12-21 tors contributing to death from asthma (5). Furthermore, blunted perception of acutely induced bronchoconstriction (6) and of dyspnea induced by inspiratory resistive loads (7) was found in subjects with asthma who experienced a near fatal asthma episode.

Hyperinflation of the lung and its unfavorable consequences on respiratory muscle function are believed to contribute to breathlessness during acute bronchoconstriction in asthma (8, 9). However, neither the exact mechanisms which cause breathlessness during bronchoconstriction in asthma nor the relationship between perception of breathlessness and histological changes in the airway mucosa is known. Individual perception of breathlessness associated with the bronchoconstriction induced by histamine, antigen exposure, or exercise is similar in early asthmatic responders (10), whereas dual responders to inhaled antigens perceive bronchoconstriction more intensely during the early than during the late asthmatic response (11). Although the lymphocyte and the eosinophil are the predominant infiltrating cells in airway mucosa of asthmatic subjects (12), the eosinophil is believed to be a primary cell responsible for the development of many of the features of asthma, including damage and desquamation of the respiratory epithelium (13), airway hyperresponsiveness (14), and allergen-induced late asthmatic reactions (15). Furthermore, the degree of infiltration of the bronchial wall by eosinophils is related to the clinical severity of asthma (16). These results led us to hypothesize that perception of breathlessness associated with bronchoconstriction may be influenced by the type of bronchoconstrictor mediator and by the degree of eosinophilic infiltration that is present in airways during the late asthmatic response (15). There are no data about the effects of corticosteroids on the perception of breathlessness associated with bronchoconstriction in asthmatic subjects.

We studied the characteristics of the perception of bronchoconstriction induced by two different types of mediators in asthmatic patients: methacholine, known to act directly on the airway smooth muscle, and bradykinin, a potent proinflammatory mediator (17) which has an additional action on airway sensory nerves (18-21) and is endogenously produced in the lung of asthmatic patients (22). We examined the relationship between breathlessness associated with agonist-induced bronchoconstriction and the pathological features of the airway mucosa of patients with asthma. We also examined the influence of inhaled corticosteroids on perception of bronchoconstriction induced by methacholine and by bradykinin.

\section{Methods}

\section{Subjects}

18 nonsmoking adults who met the American Thoracic Society's diagnostic criteria of asthma were studied (23). The duration of their asthma 


\begin{tabular}{|c|c|c|c|c|c|c|c|c|c|}
\hline \multirow[b]{2}{*}{ Patient } & \multirow[b]{2}{*}{ Age } & \multirow[b]{2}{*}{ Sex } & \multirow[b]{2}{*}{$\begin{array}{l}\text { Skin prick } \\
\text { test }\end{array}$} & \multirow[b]{2}{*}{$\mathrm{FEV}_{1}{ }^{*}$} & \multirow[b]{2}{*}{$\mathrm{FVC}^{*}$} & \multirow[b]{2}{*}{$\begin{array}{l}\text { Duration } \\
\text { of asthma }\end{array}$} & \multirow[b]{2}{*}{$\begin{array}{c}\text { Asthma } \\
\text { medication }\end{array}$} & \multicolumn{2}{|c|}{$\mathrm{PD}_{15}$} \\
\hline & & & & & & & & Mch & Bk \\
\hline & & & & & & $y r$ & & $\mu \mathrm{mol}$ & umol \\
\hline \multicolumn{10}{|c|}{ Subjects without flunisolide } \\
\hline 1 & 66 & $\mathbf{M}$ & + & 67 & 86 & 6 & $\mathrm{~T}, \beta$ & 0.48 & 0.003 \\
\hline 2 & 25 & $\mathbf{M}$ & + & 101 & 104 & 15 & $\beta^{\ddagger}$ & 8.20 & 0.836 \\
\hline 3 & 31 & $\mathrm{~F}$ & + & 101 & 104 & 22 & $\beta^{\ddagger}$ & 0.13 & 0.151 \\
\hline 4 & 53 & $\mathrm{~F}$ & - & 84 & 114 & 1 & $\beta^{\ddagger}$ & 0.12 & 0.106 \\
\hline 5 & 33 & $\mathbf{M}$ & + & 86 & 88 & 15 & $\beta^{\ddagger}$ & 3.95 & 0.011 \\
\hline 6 & 22 & $\mathbf{M}$ & + & 94 & 101 & 17 & $\beta^{\ddagger}$ & 13.78 & 0.778 \\
\hline 7 & 24 & $\mathbf{M}$ & + & 106 & 101 & 16 & $\beta^{\ddagger}$ & 0.41 & 0.040 \\
\hline 8 & 32 & $\mathrm{~F}$ & + & 81 & 94 & 19 & $\beta^{\ddagger}$ & 0.27 & 0.016 \\
\hline 9 & 24 & $\mathbf{M}$ & + & 86 & 118 & 20 & $\beta^{\ddagger}$ & 0.28 & 0.023 \\
\hline Mean & 34.4 & & & 89.6 & 101.1 & 14.6 & & 3.07 & 0.218 \\
\hline SEM & 5.0 & & & 4.1 & 3.6 & 2.3 & & 1.62 & 0.113 \\
\hline \multicolumn{10}{|c|}{ Subjects with flunisolide } \\
\hline 10 & 45 & $\mathbf{M}$ & + & 98 & 96 & 2 & $\mathrm{C}, \beta$ & 10.89 & 0.815 \\
\hline 11 & 45 & $\mathbf{M}$ & - & 89 & 103 & 2 & $\mathrm{~T}, \beta$ & 4.08 & 0.015 \\
\hline 12 & 24 & $\mathbf{M}$ & + & 119 & 126 & 19 & $\beta^{\ddagger}$ & 0.19 & 0.305 \\
\hline 13 & 33 & $\mathbf{M}$ & + & 86 & 88 & 16 & $\beta^{\ddagger}$ & 0.23 & 0.136 \\
\hline 14 & 22 & $\mathbf{M}$ & + & 86 & 103 & 17 & $\beta^{\ddagger}$ & NR & NR \\
\hline 15 & 22 & $\mathbf{M}$ & + & 88 & 90 & 15 & $\beta^{\ddagger}$ & 0.23 & NR \\
\hline 16 & 21 & $\mathbf{M}$ & + & 81 & 82 & 12 & $\beta^{\ddagger}$ & 0.90 & 0.374 \\
\hline 17 & 26 & $\mathrm{~F}$ & + & 79 & 93 & 22 & $\beta^{\ddagger}$ & 0.05 & 0.010 \\
\hline 18 & 24 & $\mathrm{~F}$ & + & 95 & 103 & 5 & $\beta^{\ddagger}$ & 2.55 & 0.815 \\
\hline Mean & 29.1 & & & 91.2 & 98.2 & 12.2 & & 2.39 & 0.353 \\
\hline SEM & 3.2 & & & 4.0 & 4.2 & 2.5 & & 1.32 & 0.130 \\
\hline
\end{tabular}

Mch, methacholine; $B k$, bradykinin; $C$, inhaled corticosteroid; $\beta$, inhaled $\beta$ agonist; $T$, theophylline; $N R$, not reactive. ${ }^{*}$ Percentage of predicted at inclusion. ${ }^{\ddagger}$ Used as needed.

ranged from 1 to $22 \mathrm{yr}$. The clinical severity of asthma was quoted according to standards reported previously (24). Subjects had mild or moderate perennial asthma and they were clinically stable at the time of the study. 15 patients were treated with inhaled $\beta_{2}$ agonist as needed, 2 used inhaled $\beta_{2}$ agonist regularly and theophylline, and 1 required regular inhaled corticosteroids (patient 10 ). With the exception of patient 10 , no subject received corticosteroids for at least 1 mo before inclusion. At the preinclusion visit, each patient underwent interview, chest radiography, electrocardiogram, spirometry, and skin prick tests to common airborne allergens (Dermatophagoides pteronyssinus, Dermatophagoides farinae, mixed grass pollen, mixed tree pollen, mixed weed pollen, cat fur, and dog hair) (Stallergenes, Fresnes, France). Clinical characteristics of subjects, including treatment requirements, are summarized in Table $I$. With the exception of patient 1 , who had systemic hypertension treated by nifedipine, no subject had any concomitant disease or treatment or history of exposure to occupational sensitizers. None of the subjects had a respiratory infection for at least $6 \mathrm{wk}$ before or during the study. The study conformed to the Declaration of Helsinki and was approved by the ethical committee of Cochin-PortRoyal University Hospital. Written informed consent was given by all subjects.

\section{Study design}

After inclusion, subjects were randomly assigned to one of two parallel treatment groups. In one group, subjects were asked to maintain the bronchodilator treatment alone using exclusively inhaled $\beta_{2}$ agonist as needed for 1-4 additional wk $(n=9)$. In the other group, subjects received inhaled flunisolide for $4 \mathrm{wk}(1,000 \mu \mathrm{g}$ twice a day through a 750-ml spacer device) associated with inhaled $\beta_{2}$ agonist as needed ( $n$ $=9$ ). For patient 10 (Table I), who was on treatment with inhaled flunisolide ( $500 \mu \mathrm{g}$ twice a day) during the last $3 \mathrm{mo}$, the inclusion in the treatment group with flunisolide was not randomly assigned. During study days, treatments were not changed and patients did not receive other antiasthmatic drugs. Methacholine challenge, fiberoptic bronchoscopy, and bradykinin challenge were successively performed in all patients. Bronchoscopy was performed at most $2 \mathrm{~d}$ after methacholine challenge and at least $5 \mathrm{~d}$ before bradykinin challenge. Thus, methacholine and bradykinin challenges were performed 6-9 d apart in 16 subjects. In patients 11 and 13, bradykinin challenge had been postponed to 22 and $12 \mathrm{~d}$ after methacholine challenge, respectively, because of a transitory decrease in 1-s forced expiratory volume $\left(\mathrm{FEV}_{1}\right){ }^{1}$

\section{Bronchial provocation}

Methacholine chloride and bradykinin acetate salt were obtained from Sigma Chemical Co. (St. Louis, MO). Bradykinin solutions were freshly prepared immediately before the challenge. Bronchial challenges were performed according to standard recommendations at similar time of day on every occasion (25). Briefly, on arrival in the laboratory, baseline spirometry was performed in all subjects. Aerosols were gener-

1. Abbreviations used in this paper: BAL, bronchoalveolar lavage; BM, basement membrane; $\mathrm{FEV}_{1}$, forced expiratory volume in $1 \mathrm{~s}$; FVC, forced vital capacity; $\mathrm{PD}_{15}$, dose of agonist that reduces $\mathrm{FEV}_{1}$ by $15 \%$; VAS, visual analogue scale. 
ated from a starting volume of $2 \mathrm{ml}$ in a disposable nebulizer (Minineb 5610; DeVilbiss Co., Somerset, PA) by means of a breath-activated dosimeter (FDC 88; Médipron, Paris, France) under a pressure of 1.5 bar. The nebulization time was $0.6 \mathrm{~s}$. Each dose of aerosol was delivered during a breath taken slowly (with a $2-5$-s breath-hold) from functional residual capacity to near total lung capacity. Under these conditions the nebulizer delivered $4 \mu \mathrm{l}$ per breath. During inhalation through a mouthpiece, the subjects wore a nose-clip. Airway responses were assessed by measurement of the $\mathrm{FEV}_{1}$ with an automated flowmeter ( $\mathrm{Au}$ tospiro AS500; Minato, Osaka, Japan). Challenges were preceded by the inhalation of $0.9 \% \mathrm{NaCl}$ solution ( saline), which caused no decrease in $\mathrm{FEV}_{1}>5 \%$ in any of the subjects. Doubling doses of methacholine (initial dose $40 \mu \mathrm{g}[0.2 \mu \mathrm{mol}]$ ) or bradykinin (initial dose $8 \mu \mathrm{g}$ [0.008 $\mu \mathrm{mol}]$ ) were administered until $\mathrm{FEV}_{1}$ had fallen by $20 \%$ or more from post-saline $\mathrm{FEV}_{1}$ or a total cumulative dose of $5,080 \mu \mathrm{g}(26 \mu \mathrm{mol})$ methacholine or $1,016 \mu \mathrm{g}(1 \mu \mathrm{mol})$ bradykinin was reached. $\mathrm{FEV}_{1}$ was measured in duplicate $2 \mathrm{~min}$ after each dose of methacholine and the better value was retained. $\mathrm{FEV}_{1}$ was measured at 1,3 , and 5 min after each dose of bradykinin. The $\mathrm{FEV}_{1}$ value obtained at $3 \mathrm{~min}$ after each dose of bradykinin was used in all analyses because it corresponded to the maximal bronchoconstrictor effect of this agonist in our subjects as well as in studies reported by others (26). The bronchial response to each dose of methacholine or bradykinin was expressed as the percentage of change in $\mathrm{FEV}_{1}$ from the post-saline value. The provocation dose of agonists that reduced $\mathrm{FEV}_{1}$ by $15 \%\left(\mathrm{PD}_{15}\right)$ was estimated by linear interpolation from the dose-response curve (25). $\mathrm{PD}_{15}$ was chosen because most subjects reached $15 \%$ fall in $\mathrm{FEV}_{1}$ after challenge with the two agonists.

\section{Bronchoscopy}

Bronchoscopy was performed according to the National Institutes of Health guidelines (27). Fiberoptic bronchoscopy was performed in the morning after an overnight fast. Arterial oxygen saturation and electrocardiogram were monitored continuously. A route for injection of intravenous medication and continuous supplemental $100 \% \mathrm{O}_{2}$ at 3 liters/ min by way of a nasal cannula was secured. Premedication consisted of intramuscular atropine ( $1 \mathrm{mg})$ and clorazepate $(10 \mathrm{mg})$ administered $30 \mathrm{~min}$ before the procedure. Subjects inhaled $200 \mu \mathrm{g}$ of salbutamol 20 min before bronchoscopy. Spirograms were obtained before starting the topical anesthesia and after bronchoscopy. Topical anesthesia was achieved with $2 \%$ (upper airways) and $1 \%$ (into the trachea and bronchi) lidocaine ( prewarmed at $37^{\circ} \mathrm{C}$ ) in a total dose of $380 \mathrm{mg}$. Fiberoptic bronchoscopy was performed using an Olympus BF1T20D bronchoscope (Olympus, Tokyo, Japan) which was introduced through the nose or mouth. Bronchoalveolar lavage (BAL) was performed after careful wedging of the bronchoscope tip in the internal segmental branch of the middle lobe bronchus. Three $50-\mathrm{ml}$ aliquots of prewarmed sterile $0.9 \% \mathrm{NaCl}$ solution were introduced through the suction port of the bronchoscope and aspirated immediately using gentle suction. Mucosal biopsies were taken after completion of BAL on sites that had not been touched previously by the bronchoscope. Biopsy specimens were obtained from the third bifurcation and subcarinae in the left lower lobe with FB-24K or FB-37K forceps (Olympus).

\section{Sample processing and analysis}

$B A L$. Lavage fluid was homogenized by gentle shaking, the volume was measured, and a total cell count was obtained on a Malassez cell. May-Grunwald-Giemsa and Papanicolaou stainings were performed on cytocentrifuge preparations. Slides were used for differential counting of 1,000 cells.

Bronchial biopsies. Biopsies were gently extracted from the forceps and immediately fixed in Bouin's fluid, embedded in paraffin, and 4 $\mu \mathrm{m}$ sections were obtained. Parallel sections were stained with hematoxylin and eosin and with Luna's reagent specific for eosinophil granule content (28). To avoid observer bias, slides were coded before analysis, which was performed without knowledge of the subject. Histological preparations were observed with a Leitz Aristoplan microscope (Rueil-
Malmaison, France) using an objective lens magnification of 40. Each section was integrally examined. The length of airway epithelium and of basement membrane (BM), the thickness of BM, and the area of lamina propria and of total submucosa were assessed using a computerized image system (Morphostar 4.01 video analysis software; Imstar, Paris, France). The lamina propria was arbitrarily taken as a zone 50 $\mu \mathrm{m}$ beneath the reticular BM. Total submucosa was defined as the total area beneath the reticular BM, excluding cartilage. Intact epithelium was defined by the presence of both basal and columnar cells with no appearance of metaplasia.

Shedding of the airway epithelium, thickness of BM, and lymphocyte infiltration were evaluated in sections stained with hematoxylin and eosin. Shedding of the airway epithelium was expressed as the percentage of the BM length in the section that was covered by intact epithelium (millimeters of intact epithelium/millimeters of BM length $\times 100$ ). The thickness of the total BM (which included true and reticular BM) was measured at $200-\mu \mathrm{m}$ regular intervals along the length of each section and was expressed as the mean of 10 measurements. Lymphocyte infiltration was expressed as number of cells per square millimeter of lamina propria.

Eosinophils were counted in the lamina propria, in the total submucosa, and in the intact epithelium in sections stained with Luna's reagent. The result of eosinophil count was expressed as number of cells per square millimeter of lamina propria or total submucosa and as number of cells per millimeter length of intact epithelium.

\section{Assessment of breathlessness associated with bronchoconstriction}

Visual analogue scale (VAS). Assessment of breathlessness was performed as described previously (4). Before bronchial challenges, the subjects were told they would be asked to make repeated inhalations of drugs that could modify their respiratory comfort. The subjects rated the magnitude of breathlessness on a $100-\mathrm{mm}$ horizontal VAS with the words "not at all breathless" and "worst imaginable breathless" on the left and right end, respectively. Instructions were given in a standard format to all subjects by the same observer. The perception of breathlessness referred to the sensation felt by the subject during an asthma attack in the past, irrespectively of any retro-sternal discomfort. The subjects were instructed to place a vertical mark on the line, such that its position, relative to the two extremes, indicated the magnitude of breathlessness at the moment of the assessment. Single visual analogue scales were presented on separate sheets of paper on each occasion. VAS scores were obtained before recording $\mathrm{FEV}_{1}$ at 2 and $3 \mathrm{~min}$ after each inhalation of methacholine and bradykinin, respectively, so that they were not aware of actual changes in $\mathrm{FEV}_{1}$. Breathlessness score was expressed in millimeters (from 0 to 100) and corresponded to the distance of the mark from the left end of the VAS. Changes in VAS score at any dose of agonist used were expressed as the difference (millimeters) between the given and post-saline breathlessness scores.

Relationship between changes in VAS score and bronchial obstruction in each group. In each treatment group, we studied the relationship between changes in VAS scores (millimeters) and in $\mathrm{FEV}_{1}$ (percentage) induced by methacholine and by bradykinin, using results obtained with all doses of agonists. We performed a rank correlation with all data points for all subjects. However, to avoid any possible bias in the correlation analysis, we performed this correlation using an identical number of data points for each subject. Therefore, we also studied the relationship between changes in VAS score and in $\mathrm{FEV}_{1}$ resulting from the two first doses of agonists which were reached in 15 of 18 and 17 of 18 subjects for methacholine and bradykinin, respectively.

Individual breathlessness sensitivity to agonist-induced bronchoconstriction: determination of $V A S / F E V_{1}$ slopes. We performed a linear regression analysis of changes in VAS scores on changes in $\mathrm{FEV}_{1}$ (percentage) for each challenge by using the least squares method. Individual slopes (VAS/FEV 1 slopes), intercepts, and correlation coefficients for both methacholine and bradykinin challenges were calculated. Therefore, the VAS/FEV 1 slope which is the VAS line length (millimeters) per percent change in $\mathrm{FEV}_{1}$ is an index of breathlessness 
Table II. Linear Regression Analysis of the Perception of Acute Bronchoconstriction*

\begin{tabular}{|c|c|c|c|c|c|c|c|c|}
\hline \multirow[b]{3}{*}{ Patient } & \multicolumn{4}{|c|}{ Methacholine challenge } & \multicolumn{4}{|c|}{ Bradykinin challenge } \\
\hline & \multicolumn{3}{|c|}{ 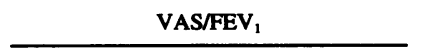 } & \multirow{2}{*}{$\begin{array}{c}\text { Maximal } \\
\text { fall in } \\
\mathrm{FEV}_{1}\end{array}$} & \multicolumn{3}{|c|}{ VAS/FEV $_{1}$} & \multirow{2}{*}{$\begin{array}{c}\text { Maximal } \\
\text { fall in } \\
\text { FEV }_{1}\end{array}$} \\
\hline & Slope & Intercept & $r$ & & Slope & Intercept & $r$ & \\
\hline & & & & $\%$ & & & & $\%$ \\
\hline \multicolumn{9}{|c|}{ Subjects without flunisolide } \\
\hline 1 & 0.88 & -1.8 & 0.968 & 19.0 & 0.08 & 0.0 & 1.000 & 34.9 \\
\hline 2 & 1.57 & 6.7 & 0.911 & 23.5 & 1.47 & -0.1 & 0.741 & 17.2 \\
\hline 3 & 0.15 & 0.0 & 1.000 & 22.8 & $(0.07)$ & $(0.4)$ & 0.411 & 23.2 \\
\hline 4 & 0.08 & 0.0 & 1.000 & 24.6 & 0.00 & 0.0 & - & 33.2 \\
\hline 5 & 1.03 & 0.0 & 0.993 & 24.0 & 0.69 & 1.4 & 0.977 & 31.1 \\
\hline 6 & 1.26 & 3.9 & 0.897 & 28.3 & 1.47 & 10.1 & 0.743 & 18.5 \\
\hline 7 & 0.51 & 0.8 & 0.986 & 22.6 & 0.22 & -1.3 & 0.956 & 42.4 \\
\hline 8 & 1.17 & -2.9 & 0.965 & 33.8 & 0.82 & -1.6 & 0.970 & 20.7 \\
\hline 9 & 0.18 & -0.7 & 0.967 & 32.3 & 0.14 & 0.4 & 0.973 & 33.7 \\
\hline Mean & 0.76 & 0.67 & 0.965 & 25.7 & $0.61^{\ddagger \S \|}$ & $1.11^{\|}$ & 0.846 & 28.3 \\
\hline SEM & 0.18 & 0.98 & 0.012 & 1.6 & $0.21^{\| \prime}$ & $1.32^{\| 1}$ & 0.073 & 2.9 \\
\hline \multicolumn{9}{|c|}{ Subjects with flunisolide } \\
\hline 10 & 1.18 & 2.5 & 0.983 & 35.8 & 0.84 & -0.5 & 0.757 & 17.6 \\
\hline 11 & 0.86 & 3.1 & 0.963 & 23.3 & 0.87 & 0.7 & 0.882 & 22.0 \\
\hline 12 & 0.32 & -1.7 & 0.967 & 47.8 & 0.18 & -0.7 & 0.915 & 23.4 \\
\hline 13 & 0.57 & -1.2 & 0.995 & 40.3 & 0.85 & 1.7 & 0.836 & 25.9 \\
\hline 14 & 2.42 & -4.0 & 0.773 & 8.0 & - & - & - & 0.0 \\
\hline 15 & 1.05 & 5.6 & 0.927 & 40.0 & $(0.44)$ & (10.0) & 0.269 & 9.8 \\
\hline 16 & 2.62 & -8.3 & 0.942 & 23.9 & 1.91 & 4.8 & 0.914 & 19.0 \\
\hline 17 & 1.07 & 0.0 & 1.000 & 66.7 & 1.82 & -8.0 & 0.968 & 40.9 \\
\hline 18 & 0.84 & 2.7 & 0.856 & 18.0 & 1.92 & -3.6 & 0.889 & 17.6 \\
\hline Mean & 1.21 & -0.13 & 0.934 & 33.8 & $1.20^{\prime \prime}$ & $-0.80^{\|}$ & 0.804 & 21.2 \\
\hline SEM & 0.26 & 1.41 & 0.025 & 5.9 & $0.26^{\prime \prime}$ & $1.54^{\prime \prime}$ & 0.080 & 2.5 \\
\hline
\end{tabular}

* Correlation coefficients ( $r$, slopes, and intercepts were calculated from linear regressions of changes in VAS line length (millimeters) against changes induced by each dose of agonists on $\mathrm{FEV}_{1}$ (expressed as percentage of post-saline values) using the least squares method. ${ }^{\ddagger} P<0.05$ for paired comparisons of slopes between methacholine and bradykinin challenges. $P<0.05$ for unpaired comparisons of slopes between groups. $P$ values were similar when including or excluding data of subjects in whom $r$ was $\leq 0.7$ (in parentheses; see Results). "Mean and SEM were calculated excluding values of $\mathrm{VAS}_{\mathrm{FEV}}$ slopes or intercepts in parentheses (see Results).

sensitivity for each subject: the steeper the VAS/FEV 1 slope, the better the perception of bronchoconstriction. Only when the correlation coefficient was $>0.71$ (which corresponded to a coefficient of determination $>0.50$, i.e., $50 \%$ or more of the total variation in VAS score was related to that of $\mathrm{FEV}_{1}$ ) were the linear regression analyses considered to be determined with confidence.

\section{Statistical analysis}

Comparisons of age, duration of asthma, baseline $\mathrm{FEV}_{1}$ and forced vital capacity (FVC) at inclusion, $F_{1}$ before challenges, $P_{15}$ to methacholine and to bradykinin, and maximal percentage of fall of FEV after challenges were compared using paired or unpaired Student's $t$ test as required. Nonparametric tests were used for variables such as VAS scores, VAS/FEV 1 slopes and intercepts, and histological and BAL findings because the normality of their distribution was not verified. Therefore, for these variables, comparisons between or within groups were made using either Mann-Whitney U-test or Wilcoxon signed rank test for unpaired and paired comparisons, respectively. Nonparametric correlations between data were made using Spearman's rank analysis. $P$ values were based on two-sided tests, and a $P$ value of $\leq 0.05$ was considered to indicate statistical significance. Results were expressed as mean \pm 1 SEM or as median [minimum-maximum].

\section{Results}

Patients treated with or without inhaled flunisolide did not differ significantly (Table I) in regard to their age, duration of asthma, $\mathrm{FEV}_{1}$ or FVC at inclusion, and methacholine or bradykinin $\mathrm{PD}_{15}$ ( $P>0.35$ for each comparison). Baseline $\mathrm{FEV}_{1}$ before methacholine and bradykinin challenges in the group of patients without flunisolide $(85.0 \pm 4.2$ and $89.7 \pm 4.9 \%$, respectively) and with flunisolide $(83.8 \pm 4.0$ and $81.7 \pm 3.6 \%$, respectively) were not different within groups (each paired comparison, $P$ $>0.10$ ) or between groups (each unpaired comparison, $P$ $>0.20$ ). The maximal fall in $\mathrm{FEV}_{1}$ reached in patients treated without or with inhaled flunisolide was similar after methacholine $(25.7 \pm 1.6$ and $33.8 \pm 5.9 \%$, respectively, $P>0.20)$ and after bradykinin $(28.3 \pm 2.9$ and $21.2 \pm 2.5 \%$, respectively, $P$ $>0.15$ ) challenges (Table II).

Relationship between VAS score and bronchial obstruction in each group. Post-saline VAS scores before methacholine and bradykinin challenges in the group of patients without flunisolide $(4.2 \pm 2.3$ and $2.1 \pm 0.8 \mathrm{~mm}$, respectively) and with fluniso- 


\begin{tabular}{|c|c|c|c|c|c|c|c|c|c|c|c|c|}
\hline & \multicolumn{6}{|c|}{ Subjects without flunisolide } & \multicolumn{6}{|c|}{ Subjects with flunisolide } \\
\hline & \multirow[b]{2}{*}{$n$} & \multicolumn{2}{|c|}{ Methacholine } & \multicolumn{3}{|c|}{ Bradykinin } & \multicolumn{3}{|c|}{ Methacholine } & \multicolumn{3}{|c|}{ Bradykinin } \\
\hline & & Rho & $P$ & $n$ & Rho & $P$ & $n$ & Rho & $P$ & $n$ & Rho & $P$ \\
\hline VAS scores versus agonist doses (all doses of agonists) & 9 & 0.74 & 0.0001 & 9 & 0.39 & 0.02 & 9 & 0.41 & 0.02 & 9 & 0.48 & 0.001 \\
\hline VAS scores versus $\mathrm{FEV}_{1}$ (all doses of agonists) & 9 & 0.53 & $<0.01$ & 9 & -0.16 & 0.35 & 9 & 0.80 & $<0.0001$ & 9 & 0.38 & $<0.01$ \\
\hline VAS scores versus $\mathrm{FEV}_{1}$ (two first doses of agonists) & 7 & 0.62 & $<0.02$ & 8 & 0.26 & 0.32 & 8 & 0.65 & $<0.02$ & 9 & 0.57 & $<0.02$ \\
\hline
\end{tabular}

Rho, correlation coefficient (Spearman's rank test).

lide ( $10.0 \pm 5.7$ and $10.5 \pm 4.9 \mathrm{~mm}$, respectively) were not different within groups (each paired comparison, $P>0.40$ ) or between groups (each unpaired comparison, $P>0.15$ ). In all subjects both methacholine and bradykinin induced an increase in VAS score, the intensity of which was dependent on the dose of the agonist (each, $P \leq 0.02$ ) (Table III). In subjects treated with inhaled flunisolide, both methacholine- and bradykinininduced increases in VAS score correlated with the decrease in $\mathrm{FEV}_{1}$ when all doses of agonists were analyzed $(P<0.0001$ and $P<0.01$, respectively). In contrast, in the group of subjects without inhaled flunisolide, a correlation between increase in VAS score and decrease in $\mathrm{FEV}_{1}$ was observed for methacholine $(P<0.01)$ but not for bradykinin $(P=0.35)$ (Table III and Fig. 1). Similar results were obtained when the relationship between changes in VAS score and in $\mathrm{FEV}_{1}$ was calculated using data obtained with the two first doses of agonists (Table III).

Individual breathlessness sensitivity to agonist-induced bronchoconstriction. The linear regression analysis of changes in VAS scores on changes in $\mathrm{FEV}_{1}$ induced by methacholine and bradykinin is shown in Table II. In patients 3 and 15 , whose corresponding coefficient of correlation for bradykinin challenges was $<0.71$, VAS/FEV 1 slopes $(0.07$ and 0.44 , respectively) were not included in the statistical analysis (see Methods). In patient 4, who reached a $33.2 \%$ fall in $\mathrm{FEV}_{1}$ after inhalation of the fifth dose of bradykinin, the VAS score was $0 \mathrm{~mm}$ at all doses of the agonist.

In patients without flunisolide, the VAS/FEV ${ }_{1}$ slopes were lower for bradykinin than those for methacholine $(0.61 \pm 0.21$ and $0.76 \pm 0.18$, respectively, $P<0.05)$. In contrast, with inhaled flunisolide, the VAS/FEV 1 slopes were not different between bradykinin and methacholine challenges $(1.20 \pm 0.26$ and $1.21 \pm 0.26$, respectively, $P>0.6)$. For methacholine challenges, VAS/FEV ${ }_{1}$ slopes were not different between groups $(P$ $>0.3$ ). Conversely, $\mathrm{VAS} / \mathrm{FEV}_{1}$ slopes for bradykinin-induced bronchoconstriction were lower in subjects without corticosteroids than in patients treated with inhaled flunisolide $(P$ $<0.05$ ).

In contrast with VAS/FEV 1 slopes, intercepts were not different between bradykinin and methacholine challenges in the

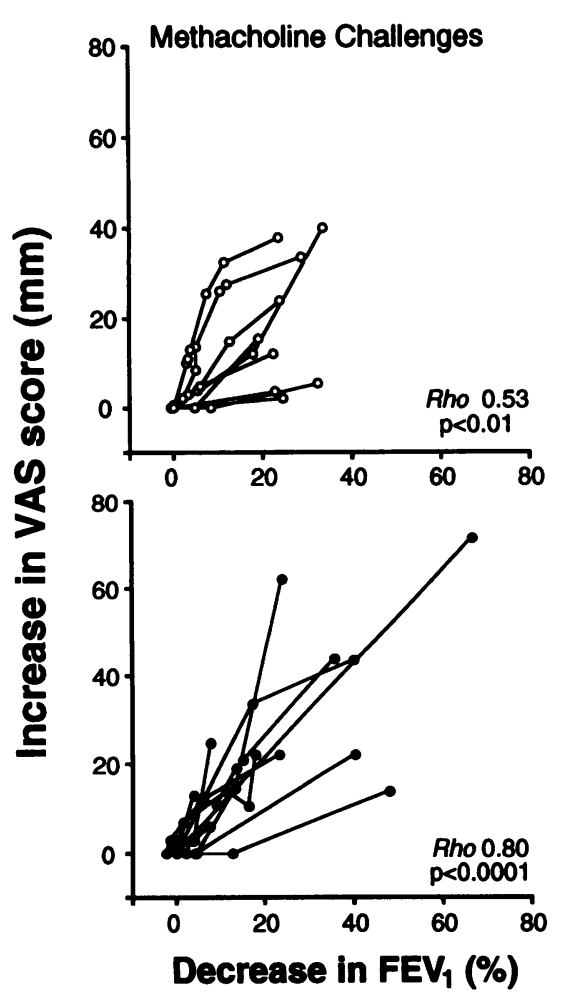

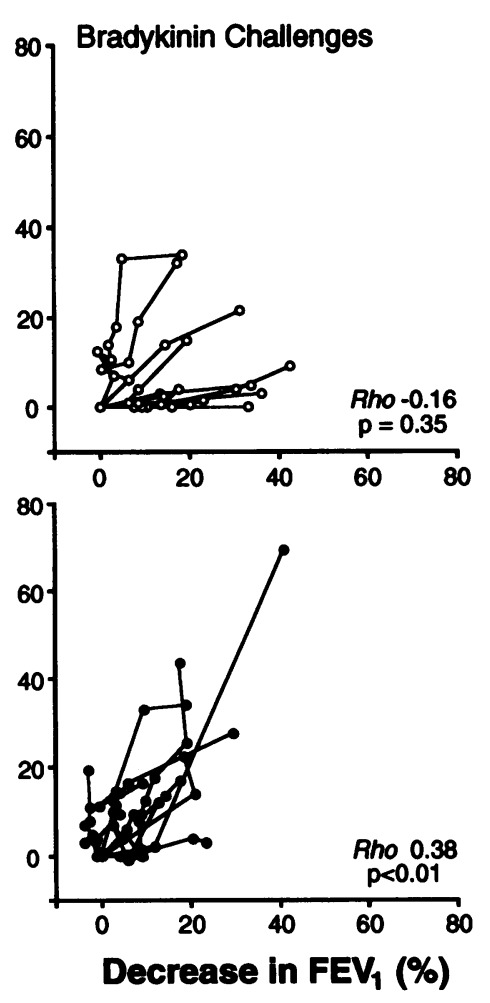

Figure 1. Correlation between changes from post-saline values in VAS score (millimeters) and in $\mathrm{FEV}_{1}$ (percentage) for methacholine challenges (left) and for bradykinin challenges (right). Open circles indicate subjects without inhaled flunisolide and closed circles indicate subjects with inhaled flunisolide. Rho, correlation coefficient (Spearman's rank test). 


\begin{tabular}{|c|c|c|c|c|c|}
\hline & $\begin{array}{l}\text { Subjects without } \\
\text { flunisolide }\end{array}$ & & $\begin{array}{l}\text { Subjects with } \\
\text { flunisolide }\end{array}$ & & $P$ values \\
\hline & & $n$ & & $n$ & \\
\hline \multicolumn{6}{|l|}{ BAL } \\
\hline Fluid recovery (\%) & $55[0-72]$ & 9 & $55[30-75]$ & 9 & 0.85 \\
\hline Eosinophils (\%o) & $15[0-64]$ & 8 & $4[0-212]$ & 9 & 0.16 \\
\hline Neutrophils (\%o) & $13[10-24]$ & 8 & $16[1-39]$ & 9 & 0.66 \\
\hline Lymphocytes (\%o) & 107 [40-289] & 8 & $85[20-310]$ & 9 & 0.85 \\
\hline Macrophages (\%o) & $856[677-950]$ & 8 & $831[640-960]$ & 9 & 0.92 \\
\hline \multicolumn{6}{|l|}{ Bronchial biopsies } \\
\hline Thickness of BM $(\mu \mathrm{m})$ & $7.4[6.7-12.7]$ & 9 & $6.3[4.5-10.3]$ & 9 & 0.17 \\
\hline BM covered by epithelium (\%) & $18.7[0.0-57.4]$ & 9 & $39.6[5.3-66.7]$ & 9 & 0.15 \\
\hline Eosinophils in submucosa (cells/mm²) & $4.5[0.0-32.4]$ & 8 & $0.0[0.0-6.5]$ & 9 & 0.09 \\
\hline Eosinophils in lamina propria (cells $/ \mathrm{mm}^{2}$ ) & $25.3[0-1,333]$ & 8 & $0.0[0.0-11.8]$ & 9 & 0.03 \\
\hline Intraepithelial eosinophils (cells/mm) & $1.2[0.0-9.2]$ & 8 & $0.0[0.0-6.2]$ & 9 & 0.31 \\
\hline Lymphocytes in lamina propria (cells $\times 10^{3} / \mathrm{mm}^{2}$ ) & $1.49[0.28-3.11]$ & 8 & $0.69[0.19-2.94]$ & 9 & 0.02 \\
\hline
\end{tabular}

* Data are expressed as median [minimum-maximum].

group without flunisolide $(1.11 \pm 1.32$ and $0.67 \pm 0.98 \mathrm{~mm}$, respectively, $P>0.7)$ and in the group with flunisolide $(-0.80 \pm 1.54$ and $-0.13 \pm 1.41 \mathrm{~mm}$, respectively, $P>0.6)$. Similarly, intercepts were not different between groups for bradykinin and methacholine challenges (each comparison, $P$ $>0.6$ ).

We have verified that including slopes and intercepts of patients 3 and 15 would not affect these results.

$B A L$ and biopsy findings and their relationship with perception of bronchial obstruction. Bronchoscopy was well tolerated in all subjects. BAL was not obtained from one subject because of insufficient recovery of the lavage fluid (patient 1, Table I). Satisfactory biopsies were obtained in all subjects except in patient 3 in whom the eosinophil count was not performed. Comparisons of BAL and histological findings between groups are shown in Table IV. There was no difference between groups in BAL recovery or differential cell count $(P>0.10)$. Conversely, asthmatic subjects without inhaled flunisolide had an increased number of eosinophils and lymphocytes in the lamina propria compared with patients treated with inhaled flunisolide ( $P=0.03$ and $P=0.02$, respectively). We found no significant differences between groups as regards the thickness of BM, the number of eosinophils in submucosa and in epithelium, and the percentage of BM covered by intact epithelium.

Bradykinin but not methacholine $\mathrm{VAS} / \mathrm{FEV}_{1}$ slopes were negatively correlated with the number of eosinophils in the submucosa $(P=0.008$ and $P=0.10$, respectively $)$, in the lamina propria $(P=0.04$ and $P=0.16$, respectively $)$, and in the epithelium ( $P=0.04$ and $P=0.06$, respectively) (Fig. 2 ). Conversely, no correlation existed between bradykinin or methacholine VAS/FEV 1 slopes and the number of lymphocytes in the lamina propria $(P=0.31$ and $P=0.89$, respectively) (Fig. 3). There was a positive correlation between methacholine or bradykinin VAS/FEV 1 slopes and the percentage of BM covered by intact epithelium $(P=0.01$ and $P=0.007$, respectively) (Fig. 4). Methacholine and bradykinin VAS $I$ $\mathrm{FEV}_{1}$ slopes did not correlate with either BAL findings or with the thickness of the BM (each correlation, $P>0.05$ ).
We have verified that including data of patients 3 and 15 would not affect these results.

\section{Discussion}

In summary, we found that, first, both methacholine and bradykinin induced a magnitude of breathlessness which was dependent on the dose of each agonist. Second, perception of breathlessness associated with acute bronchoconstriction was different for methacholine and bradykinin and was influenced by treatment with inhaled corticosteroids; for methacholine, the intensity of breathlessness was directly related to the magnitude of bronchoconstriction whatever the treatment group. In contrast for bradykinin, breathlessness was related to the magnitude of bronchoconstriction only in the group of asthmatic patients treated with inhaled flunisolide. Although a good individual correlation existed between VAS scores and bronchoconstriction in most patients, there was a wide interindividual variation in the breathlessness sensitivity associated to a given increase in bronchial obstruction (as reflected by VAS/FEV 1 slopes). The breathlessness sensitivity associated with bradykinin-induced bronchoconstriction was reduced in patients without inhaled flunisolide compared with patients with flunisolide and compared with the breathlessness sensitivity associated with methacholine-induced bronchoconstriction. Third, breathlessness sensitivity to bradykinin- but not to methacholine-induced bronchoconstriction correlated negatively with the magnitude of eosinophilic inflammation in bronchial mucosa, i.e., the more important the eosinophilic inflammation in airway mucosa, the poorer the perception of bronchial obstruction induced by bradykinin. Finally, breathlessness sensitivity associated with bronchoconstriction induced by methacholine and by bradykinin correlated positively with the percentage of basement membrane covered by epithelium, i.e., the more important the shedding of the airway epithelium the poorer the perception of bronchoconstriction induced by either agonist.

Assessment of breathlessness associated with spontaneous or provoked bronchoconstriction by using VAS has been shown 

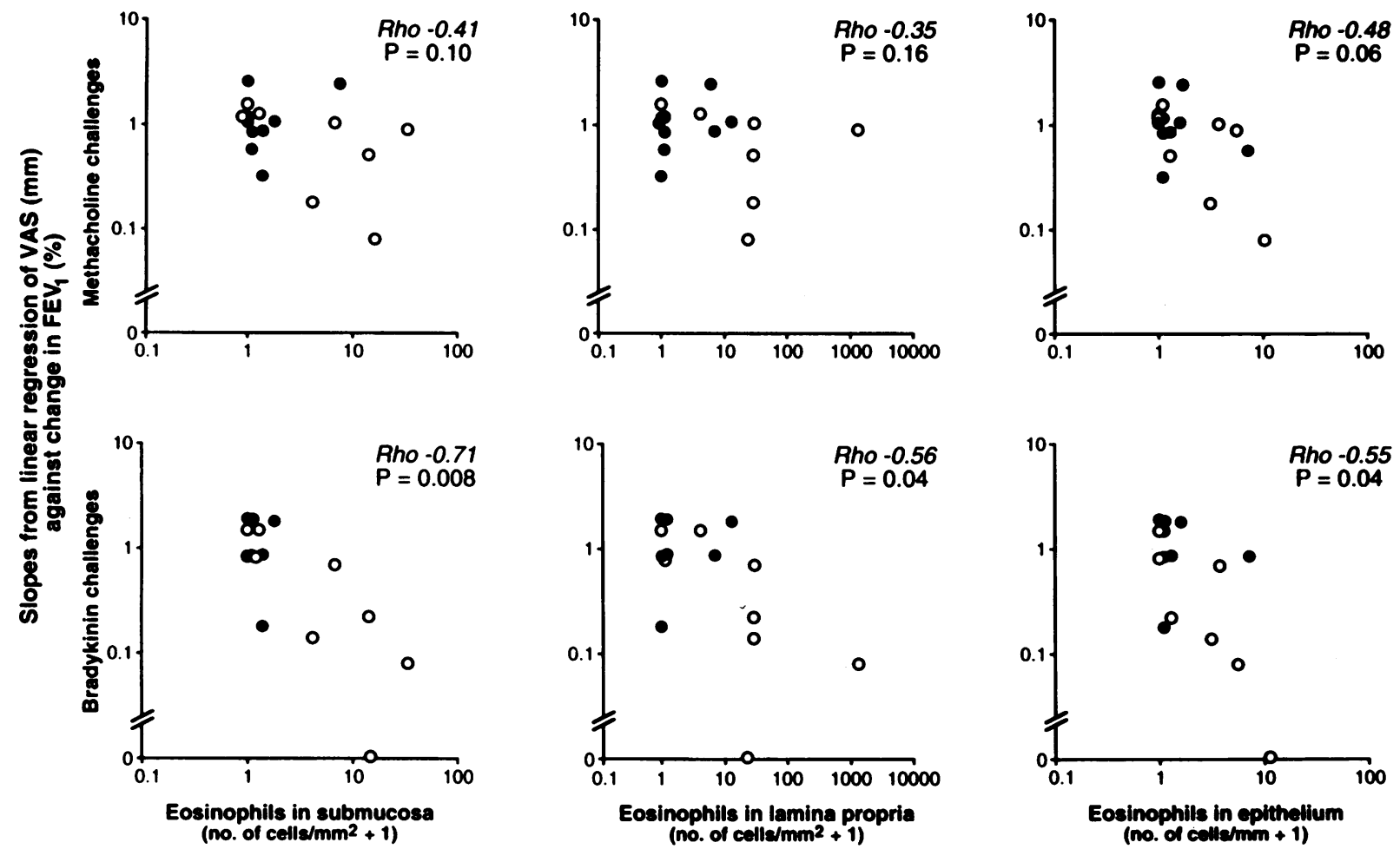

Figure 2. Correlation between methacholine and bradykinin VAS/FEV, slopes and the number of eosinophils in bronchial biopsies. VAS/FEV slopes were calculated from individual linear regression analysis of changes from post-saline values in VAS scores (millimeters) on changes in $\mathrm{FEV}_{1}$ (percentage). Open circles indicate subjects without inhaled flunisolide and closed circles indicate subjects with inhaled flunisolide. Rho, correlation coefficient (Spearman's rank test).

to be responsive and reproducible in asthmatic patients $(29$, 30). The slope of the linear regression analysis between the changes in VAS score and changes in $\mathrm{FEV}_{1}$ values allows evaluation of the individual breathlessness sensitivity to variations of airway flow $(3,31)$. In previous studies in asthmatic subjects, authors used the coefficient of correlation of this regression line to distinguish the "good perceivers" (defined as $r$ values $\geq 0.71$ ) from the "bad perceivers" (defined as $r$ values $<0.71$ ) of airway obstruction (4). However, our results show that although some subjects (patients $3,4,9$, and 12 for methacholine challenges and patients $1,7,9$, and 12 for bradykinin challenges) had high $r$ values ranging from 0.9 to 1.0 , their perception of breathlessness was poor as reflected by a low value of the VAS/FEV 1 slopes (Table II). Therefore, in our study we used the VAS/FEV 1 slopes which reflect the magnitude of breathlessness per percent change in bronchial obstruction as an assessment of individual breathlessness sensitivity.

Breathlessness associated with bronchoconstriction in asthmatic subjects originates in complex and not fully understood mechanisms. Increase in the resistive work of breathing is considered to play a role in causing breathlessness (32) through activation of proprioceptors of respiratory muscles $(33-35)$.

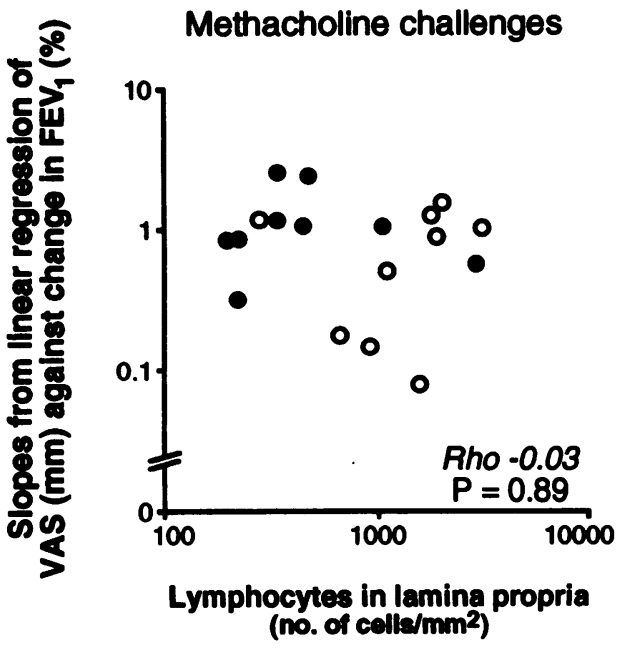

\section{Bradykinin challenges}

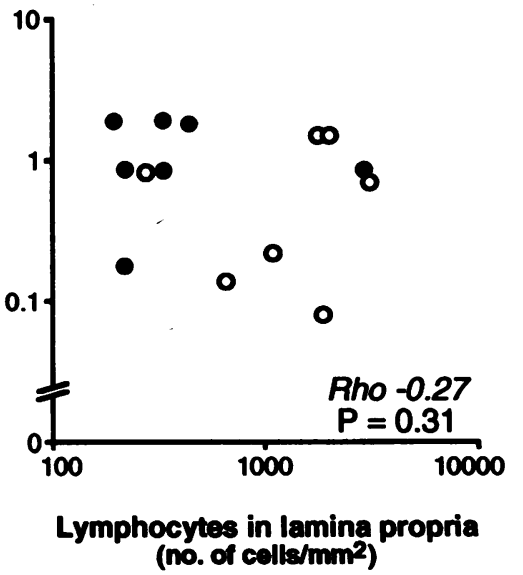

Figure 3. Correlation between methacholine and bradykinin VAS/FEV 1 slopes and the number of lymphocytes in the lamina propria in bronchial biopsies. VAS/FEV 1 slopes were calculated from individual linear regression analysis of changes from post-saline values in VAS scores (millimeters) on changes in $\mathrm{FEV}_{1}$ (percentage). Open circles indicate subjects without inhaled flunisolide and closed circles indicate subjects with inhaled flunisolide. Rho, correlation coefficient (Spearman's rank test). 


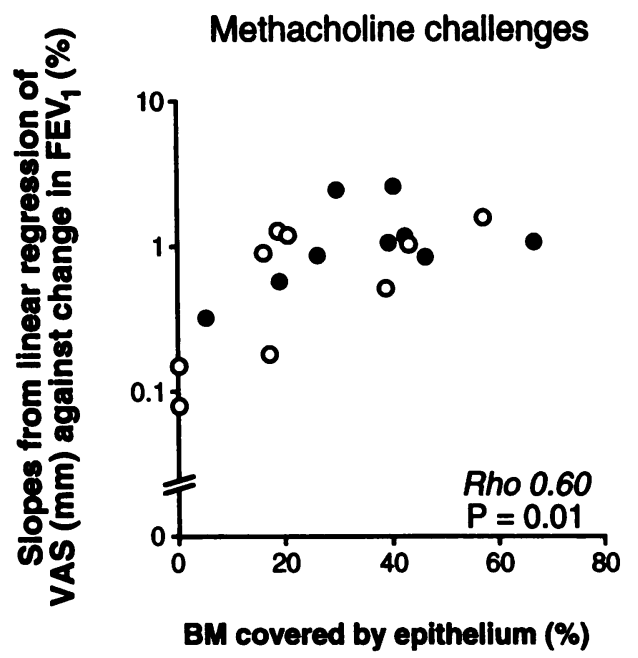

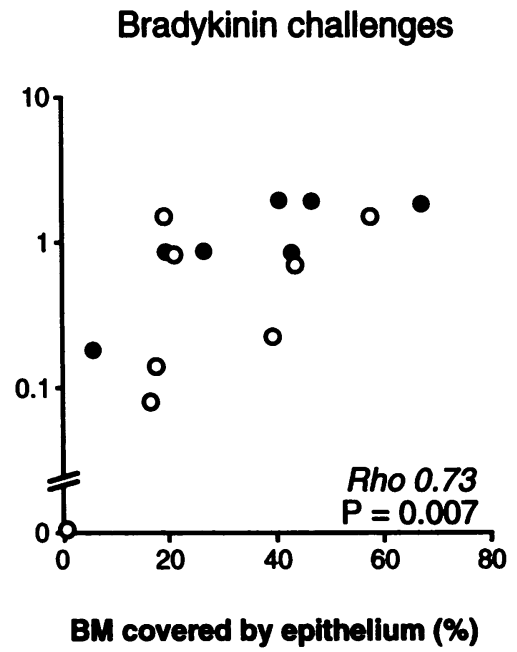

Figure 4. Correlation between methacholine and bradykinin VAS/FEV 1 slopes and the percentage of $\mathrm{BM}$ covered by epithelium. $\mathrm{VAS} / \mathrm{FEV}_{1}$ slopes were calculated from individual linear regression analysis of changes from post-saline values in VAS scores (millimeters) on changes in $\mathrm{FEV}_{1}$ (percentage). Open circles indicate subjects without inhaled flunisolide and closed circles indicate subjects with inhaled flunisolide. Rho, correlation coefficient (Spearman's rank test).
Lung hyperinflation (36) and higher airway and/or intrathoracic pressures (37) resulting from an increased airway resistance are also believed to contribute to respiratory discomfort through the activation of mechanoreceptors localized in the lung and in airways $(38,39)$. Contraction of airway smooth muscle could also stimulate directly airway mechanoreceptors (39). Besides these mechanical stimuli, airway $\mathbf{C}$ fiber endings may be directly activated by some inflammatory mediators, such as bradykinin, histamine, 5-hydroxytryptamine, capsaicin, and prostaglandins $(18,20,38,39)$. Although these receptors and the stimuli that activate them are known, their relative contribution to conscious sensation of breathlessness is not established (9). In this study we found that airway inflammation and the integrity of the airway epithelium influence the perception of induced bronchoconstriction in asthmatic patients. It is interesting to note that individuals with the largest difference between agonists in the perception of bronchoconstriction (VAS/FEV 1 slope) corresponded to those showing the greatest number of eosinophils infiltrating the airway mucosa $(1,333,29$, and 28 eosinophils/ $\mathrm{mm}^{2}$ of LP in patients 1,5 , and 7, respectively) or a low percentage of BM covered by airway epithelium ( $21 \%$ in subject 8 ). Our results strongly suggest that, besides the chest wall, the respiratory muscles, and the lung, the respiratory tract is likely to be a source of afferent information which participates in the perception of bronchoconstriction in these patients.

One of our major findings is that breathlessness associated with acute bronchoconstriction was different for methacholine and for bradykinin. Although both agonists provoked a dosedependent bronchoconstriction, the intensity of breathlessness was related to the magnitude of agonist-induced bronchoconstriction except for bradykinin in patients not treated with inhaled corticosteroids. The breathlessness sensitivity (as reflected by VAS/FEV 1 slopes) associated with bradykinin-induced bronchoconstriction was reduced in patients without inhaled flunisolide. Thus, the lack of significant relationship between VAS and the magnitude of bronchoconstriction in this group of patients was due to a poor perception of bradykinininduced bronchoconstriction.

Differences in perception of breathlessness for methacholine- and for bradykinin-induced bronchoconstriction cannot be explained by differences in the severity or duration of asthma, bronchial reactivity to methacholine or bradykinin, age, sex, or atopy status. Previous studies showed that asthmatic patients with a lowered baseline $\mathrm{FEV}_{1}$ had a reduced perception of agonist-induced bronchoconstriction as compared with patients with normal function $(1,3)$. In our study, such an hypothesis can be excluded since baseline $\mathrm{FEV}_{1}$ values did not differ between methacholine and bradykinin challenges and between groups. The maximal bronchial response was observed at a similar time period for methacholine and bradykinin ( 2 and 3 min, respectively), rendering unlikely that the difference between agonists might be explained by a difference in their rate of bronchoconstriction. Similarly, since we performed methacholine and bradykinin challenges at the same time of the day, influence of circadian variations on the perception of breathlessness during bronchoconstriction (4) can be ruled out. The intercepts of the regression lines (which reflect the threshold of perception of bronchoconstriction) and the maximal fall in $\mathrm{FEV}_{1}$ were similar between groups and between agonist challenges. Therefore, differences in the range of bronchoconstrictor stimulus from the threshold of perception of bronchoconstriction to the maximal bronchoconstrictor response cannot account for the differences in the VAS/FEV 1 slopes. Thus, the reduced perception of bronchoconstriction induced by bradykinin in asthmatic subjects not treated by corticosteroids raises the following possibilities: $(a)$ differences between methacholine and bradykinin in their site and/or mechanism of the bronchoconstrictor effect along the bronchial tree or in their mechanical effects on the respiratory system; and $(b)$ an effect of bradykinin on breathlessness that is not related to its bronchoconstrictor action.

Bronchoconstriction involving large airways is believed to be more acutely perceived than that of peripheral airways (40). Indirect arguments indicate that methacholine causes bronchoconstriction predominantly in the proximal airways $(41,42)$ whereas bradykinin may have a greater direct effect on peripheral airways $(17,19,43,44)$. However, there are no studies in vivo showing the site of bronchoconstriction induced by methacholine and bradykinin in humans. We cannot exclude the possibility that for a similar degree of bronchoconstriction, methacholine and bradykinin may vary in their mechanical effects on the respiratory system (e.g., elastance, hyperinflation) which may in turn influence the perception of bronchoconstriction. Although reduced perception of bradykinin-induced bronchoconstriction might be explained by preferential effect of this agonist on small airways and/or by different effects of agonists 
on pulmonary mechanics, it is not clear how such differences would account for the fact that perception of bradykinin-induced bronchoconstriction was impaired only in patients not treated with inhaled corticosteroids.

Though methacholine causes bronchoconstriction mainly through a direct action on the airway smooth muscle (45), bradykinin has little constrictor effect on human airway smooth muscle in vitro $(19,44)$. In asthmatic patients, bradykinininduced bronchoconstriction is mediated by both cholinergic and peptidergic reflexes $(19,46)$ involving the release of endogenous tachykinins (47). Besides its weak action on airway smooth muscle, bradykinin induces vasodilatation (48), microvascular leakage (49), and mucus secretion (50). The relative contribution of spasmogenic and nonspasmogenic effects to bradykinin-induced bronchoconstriction in asthmatic subjects is unknown. It can be hypothesized that for bradykinin the nonspasmogenic effects contributing to bronchoconstriction are substantial and poorly perceived and that they are reduced by a corticosteroid treatment.

Eosinophils seem to play an important role in the reduced perception of bronchoconstriction produced by bradykinin in patients without flunisolide. The relationship between perception of bradykinin-induced bronchoconstriction and bronchial eosinophilic inflammation is demonstrated by our findings that breathlessness sensitivity associated with bradykinin-induced bronchoconstriction was negatively related to the number of eosinophils in airway mucosa. The links between reduced perception of bradykinin-induced bronchoconstriction and eosinophilic inflammation are not clear. Eosinophils contain several active substances, among which are eosinophil-derived neurotoxin (EDN) and eosinophil cationic protein (ECP), both of which are known to have neurotoxic effects in animals $(51,52)$ and in humans (53). Thus, it may be hypothesized that afferent nerves that participate in the perception of bradykinin-induced bronchoconstriction may be impaired by neurotoxins released by activated eosinophils. Although breathlessness sensitivity associated with methacholine-induced bronchoconstriction was not significantly related to airway eosinophilic inflammation, we cannot exclude the possibility that such a relationship could be found with a greater number of subjects.

Our results suggest that the airway epithelium is involved in the sensitivity of breathlessness associated with bronchoconstriction, whatever the agonist used. The more important the shedding of bronchial epithelium, the poorer the perception of both bradykinin- and methacholine-induced bronchoconstriction. Poor perception of bronchoconstriction may result from intraepithelial nerve injury which is associated with the epithelial damage in asthma (54). Loss of epithelial cells could also reduce the production of epithelial-derived mediators such as prostanoids that may be involved in the activation of airway sensory receptors $(38,39)$. Previous studies gathered evidence that epithelial cell desquamation in asthma was the consequence of eosinophil infiltration through the release of their toxic substances $(16,55)$. Therefore, epithelial damage and perception of bronchoconstriction might both be the consequence of airway eosinophilic inflammation.

The beneficial action of inhaled corticosteroids on the perception of bradykinin-induced bronchoconstriction appears to be related to its effect on eosinophilic inflammation. Subjects treated with inhaled flunisolide had a lower eosinophilic infiltration of the airway lamina propria as compared with subjects without flunisolide treatment. Besides its action on eosinophilic inflammation, inhaled corticosteroid treatment was also demonstrated to increase the number of intraepithelial nerves and to improve the damage of the epithelium in asthmatic patients (54). Restoration of airway intraepithelial nerves and epithelial structure by corticosteroids may lead to the better perception of bradykinin-induced bronchoconstriction. Elevated amounts of both kinin and tissue kallikrein are present in the BAL of asthmatic subjects in basal conditions (22) and their concentration increases after allergen challenge (56). Thus, prolonged stimulation by endogenous kinins of airway afferent fibers which are involved in the perception of bradykinin-induced bronchoconstriction and/or repeated bronchoconstriction itself may result in a reduced awareness of the bronchial response to this agonist, a process known in sensorial physiology as temporal adaptation (57). It can be hypothesized that corticosteroids, by reducing the airway inflammation, improve the perception of bronchoconstriction. Finally, we cannot exclude the hypothesis that inhaled corticosteroids may affect perception of bronchoconstriction at the level of the central nervous system.

Elevated amounts of both kinins and tissue kallikrein are present in BAL in asthmatic subjects in basal conditions, and their concentration increases after allergen challenge $(22,56)$. The doses of inhaled kinins that provoke bronchoconstriction were shown to be of the same magnitude as the concentration of kinin-like activity measured in BAL from subjects with asthma (26). These results suggest that kinins released into the airways as a component of inflammation may be involved in spontaneous bronchoconstriction in these patients. Poor perception of bronchial obstruction induced by bradykinin in asthmatic subjects not treated by inhaled corticosteroids suggests that these patients may underestimate bronchoconstriction in conditions when endogenous mediators, such as kinins, are involved. Our results are to be put together with the observation that, for a similar decrease in airway flow, the perception of late asthmatic responses (which involves inflammatory processes) is lower than that of the early response $(10,11)$. The fact that inhaled corticosteroids rendered the patients capable of perceiving bronchial obstruction in a similar manner when bronchoconstriction was provoked by a direct stimulation on smooth muscle or by a proinflammatory mediator is of clinical interest, since poor perception of bronchoconstriction has been implicated in poor control of asthma.

\section{Acknowledgments}

We are indebted to Alain Lockhart, M.D., for his comments on earlier drafts of the manuscript and to Christian Carré for help with histological section stains.

This study was supported by a grant from Laboratoires Cassenne and by INSERM grant No. 910406. G. L. Roisman was supported in part by a grant from Fabriques de Tabac Réunies.

\section{References}

1. Orehek, J., A. Beaupré, M. Badier, M. M. Nicoli, and S. Delpierre. 1982. Perception of airway tone by asthmatic patients. Bull. Eur. Physiopathol. Respir. 18:601-607.

2. Rubinfeld, A. R., and M. C. F. Pain. 1976. Perception of asthma. Lancet. 24:882-884.

3. Burdon, J. G. W., E. F. Juniper, K. J. Killian, F. E. Hargreave, and E. J. M. Campbell. 1982. The perception of breathlessness in asthma. Am. Rev. Respir. Dis. 126:825-828.

4. Peiffer, C., J. Marsac, and A. Lockhart. 1989. Chronobiological study of the 
relationship between dyspnoea and airway obstruction in symptomatic asthmatic subjects. Clin. Sci. 77:237-244.

5. Sears, M. R. and H. H. Rea. 1987. Patients at risk for dying of asthma: New Zealand experience. J. Allergy Clin. Immunol. 80:477-481.

6. Ruffin, R. E., K. M. Latimer, and D. A. Schembri. 1991. Longitudinal study of near fatal asthma. Chest. 99:77-83.

7. Kikuchi, Y., S. Okabe, G. Tamura, W. Hida, M. Homma, K. Shirato, and T. Takishima. 1994. Chemosensitivity and perception of dyspnea in patients with a history of near-fatal asthma. N. Engl. J. Med. 330:1329-1334.

8. Lougheed, M. D., M. Lam, L. Forkert, K. A. Webb, and D. E. O'Donnell. 1993. Breathlessness during acute bronchoconstriction in asthma. Am. Rev. Respir. Dis. 148:1452-1459.

9. Killian, K. 1992. Nature of breathlessness and its measurement. In Breathlessness. N. L. Jones and K. J. Killian, editors. Boehringer Ingelheim, Hamilton, Ontario, Canada. 74-87.

10. Turcotte, H., F. Corbeil, and L. P. Boulet. 1990. Perception of breathlessness during bronchoconstriction induced by antigen, exercise, and histamine challenges. Thorax. 45:914-918.

11. Turcotte, H., and L. P. Boulet. 1993. Perception of breathlessness during early and late asthmatic responses. Am. Rev. Respir. Dis. 148:514-518.

12. Djukanovic, R., W. R. Roche, J. W. Wilson, C. R. W. Beasley, O. P. Twentyman, P. H. Howarth, and S. T. Holgate. 1990. Mucosal inflammation in asthma. Am. Rev. Respir. Dis. 142:434-457.

13. Dahl, R., P. Venge, and K. Fredens. 1988. Eosinophils. In Asthma: Basic Mechanisms and Clinical Management. P. Barnes, I. W. Rodger, and N. C. Thomson, editors. Academic Press Limited, San Diego, CA. 115-129.

14. Wardlaw, A. J., S. Dunnete, G. J. Gleich, J. V. Collins, and A. B. Kay. 1988. Eosinophils and mast cells in bronchoalveolar lavage in subjects with mild asthma. Relationship to bronchial hyperreactivity. Am. Rev. Respir. Dis. 137:6269.

15. de Monchy, J. G. R., H. F. Kauffman, P. Venge, G. H. Koeter, H. M. Jansen, H. J. Sleuter, and K. Vries. 1985. Bronchoalveolar eosinophilia during allergen-induced late asthmatic reactions. Am. Rev. Respir. Dis. 131:373-376.

16. Bousquet, J., P. Chanez, J. Y. Lacoste, G. Barnéon, N. Ghavanian, I. Enander, P. Venge, S. Ahlstedt, J. Simony-Lafontaine, P. Godard, and F. B. Michel. 1990. Eosinophilic inflammation in asthma. N. Engl. J. Med. 323:10331039.

17. Barnes, P. J. 1992. Bradykinin and asthma. Thorax. 47:979-983.

18. Kaufman, M. P., H. M. Coleridge, J. C. G. Coleridge, and D. G. Baker. 1980. Bradykinin stimulates afferent vagal $\mathrm{C}$-fibers in intrapulmonary airways of dogs. J. Appl. Physiol. 48:511-517.

19. Fuller, R. W., C. M. S. Dixon, F. M. C. Cuss, and P. J. Barnes. 1987. Bradykinin-induced bronchoconstriction in humans. Mode of action. Am. Rev. Respir. Dis. 135:176-180.

20. Fox, A. J., P. J. Barnes, L. Urban, and A. Dray. 1992. Selective activation of single vagal $\mathrm{C}$ fibres by capsaicin and bradykinin in the guinea-pig trachea in vitro. J. Physiol. 452:203P.

21. Miura, M., M. G. Belvisi, and P. J. Barnes. 1992. Effect of bradykinin on airway neural responses in vitro. J. Appl. Physiol. 73:1537-1541.

22. Christiansen, S. C., D. Proud, and C. G. Cochrane. 1987. Detection of tissue kallikrein in the bronchoalveolar lavage fluid of asthmatic subjects. J. Clin. Invest. 79:188-197.

23. American Thoracic Society. 1987. Standards for the diagnosis and care of patients with chronic obstructive pulmonary disease (COPD) and asthma. Am. Rev. Respir. Dis. 136:225-243.

24. National Heart Lung and Blood Institute. 1991. National Asthma Education Program. Expert Panel Report. Guidelines for the diagnosis and management of asthma. J. Allergy Clin. Immunol. 88(Suppl.):425-534.

25. Eiser, N. M., K. F. Kerrebijn, and P. H. Quanjer. 1983. SEPCR working group "bronchial hyperreactivity": guidelines for standardization of bronchial challenges with (nonspecific) bronchoconstricting agents. Bull. Eur. Physiopathol. Respir. 19:495-514.

26. Polosa, R., and S. T. Holgate. 1990. Comparative airway responses to inhaled bradykinin, kallidin, and [des-Arg' ${ }^{9}$ bradykinin in normal and asthmatic subjects. Am. Rev. Respir. Dis. 142:1367-1371.

27. NHLBI Workshop Summaries. 1985. Summary and recommendations of a workshop on the investigative use of fiberoptic bronchoscopy and bronchoalveolar lavage in asthmatics. Am. Rev. Respir. Dis. 132:180-182.

28. Luna, L. G. 1968. Manual of Histologic Staining Methods of the Armed Forces Institute of Pathology. McGraw-Hill, New York. 258 pp.

29. Stark, R. D., S. A. Gambles, and S. S. Chatterjee. 1982. An exercise test to assess clinical dyspnoea: estimation of reproducibility and sensitivity. $B r . J$. Dis. Chest. 76:269-278.

30. Gift, A. G., M. Plaut, and A. Jacox. 1986. Psychologic and physiologic factors related to dyspnea in subjects with chronic obstructive disease. Heart \& Lung. 15:595-601.

31. Noseda, A., J. Schmerber, T. Prigogine, and J. C. Yernault. 1993. How do patients with either asthma or COPD perceive acute bronchodilation? Eur. Respir. J. 6:636-644.

33. Campbell, E. J. M., and J. B. L. Howell. 1963. The sensation of breathlessness. Br. Med. Bull. 19:36-40.

34. Cherniack, N. 1992. Load detection and breathlessness. In Breathlessness N. L. Jones and K. J. Killian, editors. Boehringer Ingelheim, Hamilton, Ontario, Canada. 103-116.

35. Killian, K. J., and E. J. M. Campbell. 1985. Dyspnea. In The Thorax. C Roussos and P. T. Macklem, editors. Marcel Dekker, Inc., New York. 787-828.

36. Permutt, S., H. E. Fessler, R. G. Brower, and E. Kosnik. 1992. Breathlessness in acute asthma. In Breathlessness. N. L. Jones and K. J. Killian, editors. Boehringer Ingelheim, Hamilton, Ontario, Canada. 60-65.

37. Puddy, A., G. Giesbrecht, R. Sanii, and M. Younes. 1992. Mechanism of detection of resistive loads in conscious humans. J. Appl. Physiol. 72:2267-2270.

38. Karlsson, J. A., G. Sant'Ambrogio, and J. Widdicombe. 1988. Afferen neural pathways in cough and reflex bronchoconstriction. J. Appl. Physiol. 65:1007-1023.

39. Sant'Ambrogio, G. 1987. Nervous receptors of the tracheobronchial tree. Annu. Rev. Physiol. 49:611-627.

40. McFadden, E. R., Jr., R. Kiser, and W. J. deGroot. 1973. Acute bronchial asthma. Relations between clinical and physiologic manifestations. N. Engl. J. Med. 288:221-225.

41. Barnes, P. J. 1986. Neural control of human airways in health and disease. Am. Rev. Respir. Dis. 134:1289-1314.

42. Shioya, T., J. Solway, N. M. Munoz, M. Mack, and A. R. Leff. 1987 Distribution of airway contractile responses within the major diameter bronch during exogenous bronchoconstriction. Am. Rev. Respir. Dis. 135:1105-1111.

43. Mak, J. C. W., and P. J. Barnes. 1991. Autoradiographic visualization of bradykinin receptors in human and guinea pig lung. Eur. J. Pharmacol. 194:3743.

44. Molimard, M., C. A. E. Martin, E. Naline, A. Hirsch, and C. Advenier. 1994. Contractile effects of bradykinin on the isolated human small bronchus. Am. J. Respir. Crit. Care Med. 149:123-127.

45. Cockcroft, D. W., and F. E. Hargreave. 1991. Airway hyperresponsiveness: definition, measurement, and clinical relevance. In Asthma: Its Pathology and Treatment. Vol. 49. M. A. Kaliner, P. J. Barnes, and C. G. A. Persson, editors. Marcel Dekker, Inc., New York. 51-72.

46. Dixon, C. M. S., and P. J. Barnes. 1989. Bradykinin-induced bronchoconstriction: inhibition by nedocromil sodium and sodium cromoglycate. $\mathrm{Br}$. J. Clin. Pharmacol. 27:831-836.

47. Ichinose, M., N. Nakajima, T. Takahashi, H. Yamauchi, H. Inoue, and T. Takishima. 1992. Protection against bradykinin-induced bronchoconstriction in asthmatic patients by neurokinin receptor antagonist. Lancet. 340:1248-1251.

48. Corfield, D. R., S. E. Webber, Z. Hanafi, and J. G. Widdicombe. 1991. The actions of bradykinin and lys-bradykinin on tracheal blood flow and smooth muscle in anesthetized sheep. Pulm Pharmacol 4:85-90.

49. Ichinose, M., and P. J. Barnes. 1990. Bradykinin-induced airway microvascular leakage and bronchoconstriction are mediated via a bradykinin $\mathrm{B}_{2}$ receptor. Am. Rev. Respir. Dis. 142:1104-1107.

50. Baraniuk, J. N., J. D. Lundgren, H. Mizoguchi, D. Peden, A. Gawin, M. Merida, J. H. Shelhamer, and M. A. Kaliner. 1990. Bradykinin and respiratory mucous membranes. Analysis of bradykinin binding site distribution and secretory responses in vitro and in vivo. Am. Rev. Respir. Dis. 141:706-714.

51. Fredens, K., R. Dalh, and P. Venge. 1982. The Gordon phenomenon induced by the eosinophil cationic protein and eosinophil protein X. J. Allergy Clin. Immunol. 70:361-366.

52. Durack, D. T., S. J. Ackerman, D. A. Loegering, and G. J. Gleich. 1981. Purification of human eosinophil-derived neurotoxin. Proc. Natl. Acad. Sci. USA. 78:5165-5169.

53. Fredens, K., A. Tøttrup, I. B. Kristensen, R. Dahl, N. O. Jacobsen, P. Funch-Jensen, and P. Thommesen. 1989. Severe destruction of esophageal nerves in a patient with achalasia secondary to gastric cancer. A possible role of eosinophil neurotoxic proteins. Dig. Dis. Sci. 34:297-303.

54. Laitinen, L. A., A. Laitinen, and T. Haahtela. 1992. A comparative study of the effects of an inhaled corticosteroid, budesonide, and a $\beta_{2}$-agonist, terbutaline, on airway inflammation in newly diagnosed asthma: a randomized, doubleblind, parallel-group controlled trial. J. Allergy Clin. Immunol. 90:32-42.

55. Gleich, G. J. 1990. The eosinophil and bronchial asthma: current understanding. $J$. Allergy Clin Immunol. 85:422-436.

56. Christiansen, S. C., D. Proud, R. B. Sarnoff, U. Juergens, C. G. Cochrane and B. L. Zuraw. 1992. Elevation of tissue kallikrein and kinin in the airways of asthmatic subjects after endobronchial allergen challenge. Am. Rev. Respir. Dis. 145:900-905.

57. Marks, L. E. 1974. Sensory Processes. In The New Psychophysics. Academic Press, New York. 115-126. 